\title{
A TRAJETÓRIA POLÍTICA E HISTÓRICO-NORMATIVA DO ENSINO TÉCNICO DA ÁREA DE AGROPECUÁRIA NO ESTADO DE SÃO PAULO: a história política de transição por decretos (de 1882 a 2001)
}

\author{
Marta Leandro da Silva ${ }^{1}-\operatorname{Prof}^{a} \operatorname{Dr}^{\mathrm{a}}$ UNESP-FCLAR \\ co-autor Waldemar Marques²- UFSCAR
}

\section{RESUMO}

Este artigo apresenta a trajetória histórica do ensino técnico agrícola no Estado de São Paulo, de 1882 a 2001, com destaque para os aspectos normativos e políticos de transição de órgãos gestores e ruptura na construção e consolidação de um projeto pedagógico-curricular desta área do ensino técnico e de políticas institucionais dessas escolas técnicas. Focaliza, assim, as importantes mudanças de caráter político-normativas e pedagógico-organizacionais que delinearam a construção da sua especificidade.Isto porque é necessário conhecer a história do ensino técnico 'agrícola' (área agropecuária) a fim de subsidiar a análise de sua configuração atual e divisar novas perspectivas para sua gestão.O ensino agrícola paulista foi alvo de constantes indefinições políticas quanto aos seus princípios e fins.As várias transferências e realocações a que foi submetido passando por diferentes Secretarias Estaduais, revelam os entraves políticos quanto à sua gestão e a dificuldade de situá-lo em um locus apropriado e condizente aos seus fins.

Palavras-Chaves: trajetória político-normativa, ensino técnico agrícola, Estado de São Paulo

\begin{abstract}
This article presents the historical trajectory of agricultural technical education in the State of São Paulo, 1882-2001, with emphasis on regulatory and policy aspects of transition management agencies and disruption in the construction and consolidation of a pedagogical and curricular design of this area of teaching technical and institutional policies of these technical schools. Thus focuses on the major changes in the political-normative and pedagogical and organizational character that shaped the construction of its especificidade.Isto because it is necessary to know the history of technical education 'agricultural' (agricultural area) in order to support the analysis of its configuration current and devise new prospects for your gestão.O Paulista agricultural education was subject to constant political uncertainties as to its principles and fins.As several transfers and reallocations it has undergone through different State Secretariats, reveal political barriers regarding its management and the difficulty of situating it in an appropriate and befitting their purposes locus.
\end{abstract}

Key-words: Key-words: political and normative trajectory, agricultural technical school, State of Sao Paulo

\footnotetext{
${ }^{1}$ Marta Leandro da Silva - $\operatorname{Prof}^{\mathrm{o}} \operatorname{Dr}^{\mathrm{a}}$ da UNESP- Faculdade de Ciências e Letras de Araraquara- Departamento de Ciências da Educação. Doutora em Educação (UNESP). Ė líder do Grupo de Pesquisa Inter-institucional em Políticas, Gestão, Avaliação, História e Memória da Educação Profissional e Tecnológica (GEDPROTEC).

${ }^{2}$ Waldemar Marques $-\operatorname{Prof}^{\circ} \operatorname{Dr}^{\circ}$ Orientador da Pesquisa de Mestrado pelo PPGE da UFSCAR e atualmente $\operatorname{Prof}^{\circ} \operatorname{Dr}^{\circ}$ da Universidade Federal de São Carlos/SP- Campus Sorocaba
} 


\section{INTRODUÇÃO}

Este artigo reporta-se à pesquisa de mestrado $^{3}$ e busca apresentar a trajetória histórico-política do ensino técnico agrícola no Estado de São Paulo, de 1882 a 2001, com destaque para a análise dos aspectos normativos e políticos de transição de órgãos gestores e ruptura na construção e consolidação de um projeto pedagógico-curricular desta área do ensino técnico e de políticas institucionais das escolas técnicas. Focaliza, assim, as importantes mudanças político-normativas e pedagógico-organizacionais que delinearam a construção da sua especificidade

É necessário conhecer a história deste ensino a fim de subsidiar a análise de sua configuração atual e divisar novas perspectivas para sua gestão. Isto pois, "a essência humana é histórica num duplo sentido: a ) na medida em que só se dá historicamente; b) na medida em que ela mesma é um produto histórico". (SÁNCHEZ VÁSQUEZ, 1977, p. 425). Outrossim, o ensino técnico agrícola constitui-se em raro objeto de pesquisas sendo inegáveis as dificuldades de acesso às fontes e à preservação de dados históricos. Conforme afirma Shigeo Mizoguchi (197-?, p. 3) "na realidade não se têm elementos rigorosamente históricos para uma apreciação das origens e evolução do ensino da agricultura no Brasil antes do século XX”. A educação profissional (em especial o nível técnico destinado à área de agropecuária) traz marcas indeléveis dos traços coloniais escravocratas e resquícios dessa visão cultural preconceituosa e depreciativa em relação à formação para o trabalho.

\section{1- O ENSINO TÉCNICO AGRÍCOLA PÚBLICO NO ESTADO DE SÃO PAULO: transição e ruptura na política educacional (de 1886 a 2001)}

Em primeira instância, é válido ressaltar a importância político-econômica que a então Província de São Paulo (Estado de São Paulo) adquire no fim do Império, sedimentado na lavoura cafeeira já apresentava as bases de um embrionário sistema industrial. Segundo Fernando de Azevedo (1971) essa situação de prosperidade permitiu que o Estado de São Paulo lançasse as bases para um sistema próprio de educação, especialmente do ensino técnico agrícola, da área agropecuária. Isto porque foi para São Paulo onde se deslocou o centro econômico instigando ao desenvolvimento da educação pública nos seus diversos níveis e modalidades.

\footnotetext{
${ }^{3}$ Dissertação de Mestrado (Área Fundamentos da Educação) apresentada em 2002 ao PPGE da UFSCAR(São Carlos/SP) intitulada “ A Reforma da Educação Profissional Técnica de Nível Médio: impactos e impasses para o Ensino Técnico Agrícola no Estado de São Paulo" sob a orientação do Waldemar Marques $-\mathrm{Prof}^{\circ} \mathrm{Dr}^{\circ}$ do PPGE/UFCSAR .
} 
Outro fator importante foi a adoção de uma política de financiamento da imigração, subsidiada pelo Estado de São Paulo, a partir de 1886, desencadeando novas perspectivas ao trabalho de colonos, com a abolição do regime escravocrata. Outrossim, o desenvolvimento da lavoura cafeeira e alta de preço do café que atingiu um dos seus pontos culminantes em 1895 atraiu maiores correntes de imigração para essa região. Como bem explicita Azevedo (1971),

\begin{abstract}
essa situação de prosperidade que se prolongou até 1928, na economia rural, com fundamento na lavoura do café, e a que o surto das indústrias, sobre tudo a partir de 1918, devia dar um impulso vigoroso, permitia ao Estado de São Paulo organizar em bases mais sólidas e largas o seu sistema de educação. [...] O Instituto Agronômico, estabelecido em Campinas pelo governo imperial em 1887, transfere-se em 1892 para o domínio do Estado de São Paulo. (AZEVEDO, 1971, p. 583).
\end{abstract}

Relembramos que, no período imperial, o Ensino Agrícola recebe alguma atenção, com a criação de instituições escolares destinadas à formação de profissionais para o setor primário. A transferência do Instituto Agronômico situado em Campinas/SP para a esfera político-jurídica do Estado de São Paulo muito contribuiu para o fomento do setor agrícola, bem ainda para estudos, pesquisas e desenvolvimento de tecnologia nessa região.

Entretanto, é na primeira fase da República que constatamos o maior desenvolvimento e expansão do ensino técnico agrícola paulista. As mudanças no contexto político-econômico acarretam implicações no plano educacional, trazendo à tona a questão da formação profissional. Intensificam-se a oferta de serviços técnicos do setor agropecuário e incentivos à pesquisa e experimentação agrícolas. Há necessidade de ampliação de instituições para formação de profissionais de nível técnico no setor agropecuário, sedimentado na lavoura cafeeira, o pilar de sustentação da economia agroexportadora da primeira república.

No início do período republicano a lavoura do café, tendo se iniciado no Rio de Janeiro, passando pelo Vale do Paraíba, expandiu-se para o oeste paulista. Os grandes fazendeiros de café do Estado de São Paulo organizaram a infra-estrutura para a expansão e consolidação da lavoura cafeeira, propiciaram e incentivaram a construção de rede ferroviária facilitando o acesso ao porto de exportação na cidade de Santos.

Diante desse contexto pode-se dizer que o Estado de São Paulo constituíu-se em um dos grandes centros difusores do Ensino Agrícola no Brasil, deixando as marcas de seu pioneirismo. Em 1882 foi criado o Liceu de Artes e ofícios na capital de São Paulo, que tinha por objetivo ministrar gratuitamente a formação profissional mediante o oferecimento de cursos relacionados às artes e ofícios incluindo cursos da área primária. Já em 1885 foi criada a Escola Agrícola "Luiz de Queiróz" em Piracicaba, subordinada à Secretaria de 
Agricultura, tendo sido o grande centro difusor do Ensino Agrícola no Estado de São Paulo, alcançando projeção nacional. Em 1931, mediante o decreto $n^{\circ}$ 5.206, de 24/9/31 a Escola Agrícola transformou-se na atual Escola Superior de Agricultura "Luiz de Queiroz", da Universidade de São Paulo.

Na verdade, é no âmbito da Secretaria da Agricultura que surgem as primeiras iniciativas de organização do ensino agrícola no Estado de São Paulo. Segundo Lourdes M. Machado ${ }^{4}$ (1992, p.44) com essas iniciativas “o governo do Estado de São Paulo antecede o governo federal na organização do ensino agrícola e das atividades do setor agrário da economia [...]". Já no final do século XX tem-se organizado o Serviço Agronômico do Estado, sendo prevista a criação de escolas práticas elementares de agricultura, com a instituição de distritos agrícolas sob a responsabilidade de um inspetor de agricultura. Segundo Schimidt e Reis (1942, p 19-20) apud Machado ( 1992, p. 44), no ano de 1900,

\begin{abstract}
foi criada, por iniciativa dos inspetores de agricultura, uma Escola Municipal de Agricultura em Batatais [...] A Escola de Trabalhadores Rurais, em Araras, organizada por colaboração da Prefeitura Municipal e da Secretaria da Agricultura, e o Aprendizado Agrícola Dr "Bernardino de Campos", em Iguape, sob a direção do Inspetor de Agricultura do distrito, são realizações do ano de 1902 [...] é instalado o Aprendizado Agrícola "João Tibiriçá" (São Sebastião), em 1905.
\end{abstract}

Com a regulamentação do Ensino Agrícola no Brasil, por meio da publicação do Decreto Federal no 8.319, de 20/11/1910, o Estado de São Paulo cria os seus dois primeiros Aprendizados Agrícolas localizados nos municípios de Iguape e São Sebastião. Estes Aprendizados Agrícolas visavam à formação de chefes de culturas, administradores e capatazes. Contudo, dadas as condições adversas eles não mantiveram o êxito inicial, entrando em decadência, em função de alguns fatores interferentes, tais como: a) a criação, em quase todos os estados, de organizações do mesmo gênero; b) a insuficiência, ou mesmo a inexistência, de agrônomos para dirigi-los; c) o desenvolvimento de projetos não condizentes com as condições infraestruturais e com seus fins e objetivos, como também com às reais condições econômicas do país; d) desorganização na estrutura administrativa-contábil e financeira, apresentando gastos sem critérios.

Por outro lado, como exceção merece destaque o Patronato Agrícola "José Bonifácio", criado em 1921 e posteriormente transferido para a esfera estadual em 1934. O

\footnotetext{
${ }^{4}$ Para análise da relação trabalho-educação no ensino técnico agrícola indicamos MACHADO, L. M. Ensino Agrícola no Estado de São Paulo: introdução ao estudo relação trabalho-educação. 1992. Dissertação (Mestrado em Educação) Faculdade de Filosofia e Ciências, Universidade Estadual Paulista, Marília, 1992. A pesquisa desenvolvida (no âmbito do mestrado) pela $\operatorname{Prof}^{\mathrm{a}} \operatorname{Dr}^{\mathrm{a}}$ Lourdes Marcelino Machado (PPGE -UNESP Marília) é muito valiosa para a análise histórica do ensino técnico no Estado de São Paulo pois apresenta contributos importantes para a educação profissional técnica 'paulista'.
} 
Patronato Agrícola "José Bonifácio" constituíu-se no núcleo embrionário do Colégio Técnico Agrícola "José Bonifácio", sediado no campus da Universidade Estadual Paulista "Júlio de Mesquita Filho", em Jaboticabal. Tal instituição escolar é destacadamente um referencial que revela compromisso político-pedagógico com o ensino técnico agrícola paulista constituindose num frutífero modelo de escola técnica agrícola, que vem, ao longo do tempo, cumprindo seu objetivo educacional com êxito.

Pode-se dizer que, até a década de trinta, a educação profissional da área primária, no Estado de São Paulo, centralizava-se prioritariamente nas escolas que ofereciam formação elementar agrícola. Verifica-se, no entanto, que o sistema de ensino agrícola no Brasil e especialmente no Estado de São Paulo contemplava ao longo de sua evolução, diferentes tipos de escolas, que ofereciam diferentes modalidades e níveis de ensino agrícola, subordinadas também a diferentes órgãos gestores. Enfim, não havia um sistema de ensino agrícola no Estado de São Paulo, como no país, baseada em uma filosofia político-pedagógica direcionada especificamente para esse ensino (área profissional). A coexistência simultânea de diversos órgãos coordenadores, diferentes instituições escolares, sem a definição dos princípios, fins e objetivos da educação profissional destinada à área agropecuária revelam a complexidade desta situação e as controvérsias e impasses no âmago das políticas governamentais direcionadas à gestão do ensino agrícola no Estado de São Paulo.

Shigeo Mizoguchi ${ }^{5}$, professor e engenheiro agrônomo, importante pesquisador e ativo protagonista do ensino agrícola destaca três grandes momentos na evolução do Ensino Agrícola no Estado de São Paulo: $1^{\circ}$ ) O Ensino da Agricultura na Secretaria da Educação ; $2^{\circ}$ ) O Ensino Agrícola na Secretaria da Agricultura ; $3^{\circ}$ ) A diretoria do Ensino Agrícola.

Utilizaremos a periodicização supracitada a fim de sistematizar as fases de evolução do ensino agrícola e seus grandes marcos. A esse respeito, Mizoguchi também ressalta a complexidade de se explicitar a evolução do Ensino Agrícola paulista, pois,

\begin{abstract}
vários tipos de escolas de agricultura em vários níveis de escolaridade estiveram funcionando concomitantemente no Estado de São Paulo, subordinadas algumas à Secretaria da Educação e outras à Secretaria da Agricultura, e de que algumas escolas estiveram subordinadas a ambas Secretarias em épocas diferentes .[...] Esse fato por certo veio dificultar a tarefa de pesquisa histórica do Ensino Agrícola no Estado[...] e a complexidade do assunto torna-se bastante evidente. (MIZOGUCHI, 1980, p. 16).
\end{abstract}

\footnotetext{
5 Para um estudo aprofundado sobre o Sistema Escola-Fazenda no Ensino Técnico Agrícola indicamos a leitura dos textos de Shigeo Mizoguchi : MIZOGUCHI, S. Escola-Fazenda: um sistema brasileiro onde o jovem aprende, trabalha e ganha. São Paulo: CENAFOR, 1980. Trabalho apresentado no Seminário Internacional de Educação, Formação Profissional e Emprego nas periferias urbanas, Salvador, 1980.
} 
O desenvolvimento do Ensino Agrícola na Secretaria da Educação, no Estado de São Paulo, compreende o período de 1934 a 1955. (MIZOGUCHI, 1980).

Em 1934, é criada a Superintendência da Educação Profissional e Doméstica, órgão subordinado à Secretaria Estadual de Educação, com a finalidade de atender às necessidades crescentes do Ensino Profissional. Sua criação tinha por objetivo unificação das diretrizes gerais administrativas e pedagógicas, estabelecendo normas e critérios uniformes a serem seguidos pelas escolas profissionais do Estado de São Paulo. Foi então elaborado um plano pedagógico específico para o ensino agrícola, que objetivava a formação profissional de jovens de ambos os sexos, em técnicas e ofícios, preponderantemente manuais e mecânicos, direcionados à Agricultura. Essa Superintendência argumentou quanto à necessidade de formação profissional de técnicos da área agrícola, nos seguintes termos,

\begin{abstract}
nosso aparelho em ensino técnico até há bem pouco tempo limitara suas atividades em manter institutos e escolas de índole industrial e doméstica. Entretanto, a vasta zona de cultura paulista aí está a clamar a substituição dos seus condutores improvisados, por elementos aptos que tornem o labor das fazendas mais eficaz e mais de acordo com a técnica moderna. [...] Eis o fundamento que levou o Governo a ampliar o aparelho do ensino profissional com esta interessante modalidade. (MIZOGUCHI, 1980, p. 8).
\end{abstract}

Em atenção ao referido plano, o governo estadual criou em 1935 mediante o Decreto $\mathrm{n}^{\mathrm{o}}$ 7.073, de 6 de abril, a Primeira Escola Estadual destinada à formação profissional de nível médio da área agrícola denominada Escola Profissional Agrícola Industrial e Mista localizada no município de Espírito Santo do Pinhal, cujo regimento e estrutura de funcionamento serviria de modelos para as demais. Em continuidade a este Plano foram criadas duas outras escolas técnicas agrícolas sendo uma em Jacareí, neste mesmo ano e outra em São Manuel, em 1939. No entanto, tais instituições não funcionaram nos termos da Escola Profissional Agrícola Industrial Mista de Espírito Santo do Pinhal.

Nesse período também foram criadas as Escolas e cursos profissionais, mediante regime de cooperação com prefeituras municipais, com as Diretorias de Estradas de Ferro do Estado (Cursos Ferroviários), com instituições particulares e filantrópicas, como o Aprendizado Agrícola Industrial anexo ao Educandário D. Duarte, destinado a jovens do sexo masculino.

As Escolas Profissionais Agrícolas Industriais e Mistas tinham por objetivos: formar profissionais de nível médio para o setor primário: os Mestres de Cultura, Capatazes e Administradores Agrícolas, difundir os conhecimentos científicos e novas técnicas agrícolas, e formar donas-de-casa com orientação para atividades rurais . 
A localização e distribuição dessas Escolas atenderia ao estudo rigoroso do meio ambiente da região na qual seriam implantadas.

Com relação à estrutura e funcionamento, as Escolas Profissionais deveriam funcionar com duas sedes:

a) uma sede em zona urbana, onde funcionavam as classes, laboratórios e oficinas industriais. Esta idéia de manter uma sede da escola na cidade tinha por objetivo aproximar os alunos da zona urbana para os cursos, e a de não separar abruptamente os educandos do convívio familiar;

b) uma sede na zona rural, instalada na fazenda da escola. Esta sede rural servia de campo experimental, denominado Campo-Escola, onde seriam desenvolvidas as práticas agrícolas, em regime de internato, através de estágios.

É importante explicitar a sistemática de internato por estágio. O estágio funcionava em regime de rotatividade cidade-campo. O estágio na sede da cidade era necessário para o desenvolvimento das disciplinas da parte propedêutica e trabalhos de aprendizagem nas oficinas. O estágio no campo era realizado em regime de internato, para o estudo das técnicas e práticas agrícolas. Este objetivava levar o educando a conhecer e vivenciar situações reais da agropecuária, da vida rural, socializando-o com o meio em que iria atuar profissionalmente. Este estágio era organizado da seguinte forma: a) para os alunos do $1^{\mathrm{o}}$ ano apenas uma semana de estágio interno; b) para os alunos do $2^{\circ}$ ano, duas semanas c) para os alunos do $3^{\circ}$ ano, três semanas; d) no $4^{\circ}$ ano o estágio seria feito na fazenda, em regime de internato, durante todo o ano letivo.

As Escolas Profissionais Agrícolas Industriais e Mistas deveriam receber alunos de ambos os sexos, oriundos ou não da zona rural, dos municípios circunzivinhos, de outras regiões, bem como alunos de outros Estados. Havia reserva de um terço da vagas para os candidatos do município sede da escola. Não sendo estas preenchidas poderiam ser oferecidas aos demais interessados. Quando o número de candidatos fosse superior ao número de vagas, havia a seleção mediante a realização de uma seleção. As condições de matrícula eram: a) ter quatorze anos completos para o sexo masculino e treze para o sexo feminino; b) ser vacinado e não sofrer de doença contagiosa;c) ser concluinte do grupo escolar; d) ser aprovado em exame de Português e Matemática, em nível exigido para a matrícula no $1^{\circ}$ ginasial.

Os Cursos oferecidos pelas Escolas Profissionais Agrícolas Industriais Mistas estavam organizados da seguinte forma:

a) Curso Primário Profissional, destinado à formação de operários agrícolas e donasde-casa orientadas para as atividades agrícolas, com duração de três anos; 
b) Curso Complementar destinado à formação integral de mestres de culturas, capatazes e de administradores agrícolas, com duração de um ano.

Ambos os cursos deveriam incluir cultura geral e formação profissional. As disciplinas da parte técnico-profissional abrangiam duas seções: a industrial e a agrícola. Para os alunos, a seção agrícola compreendia as disciplinas de: Agricultura Geral, Agricultura Especializada, Noções de Zootecnia e Veterinária, Máquinas Agrárias, Noções de Agrimensura, Nivelamento, Irrigação e Drenagem, Química Agrícola. Para as alunas, compreendia: Criação, Laticínios, Horticultura e Jardinagem.

Aos concluintes dos cursos de Mestres de Cultura, Capatazes e Administradores Agrícolas seriam entregues os respectivos diplomas somente após a realização de estágio de um ano na Fazenda da Escola, nos estabelecimentos agrícolas estaduais ou em propriedades particulares, mediante atestado de capacidade técnica, passado pelo diretor ou proprietário.

A Fazenda-Modelo seria o ambiente didático-pedagógico, o espaço experimental (laboratório ambiental) para o desenvolvimento das técnicas e práticas agrícolas, sendo constituído de uma seção feminina (Casa-Ambiente com alojamento, jardim, horta, aviário etc) e de uma seção masculina (Campo-Escola).

O Campo-Escola, para a seção masculina, seria o ambiente didático-pedagógico de adaptação dos alunos às atividades agrícolas, sendo subdividido em duas seções: a) seção de cultura: áreas cultivadas, seção de sementeiras, preparo de mudas, ripado, estufas e culturas em vasos; b) seção de criação de pequeno porte.

As Escolas Profissionais Agrícolas Industriais Mistas deveriam manter também as Cooperativas Escolares de Produção e Consumo, com o objetivo de disseminar a doutrina cooperativista entre os alunos. As atividades vinculadas às Cooperativas Escolares deveriam desenvolver-se em Regime de Comunidade de Trabalho, tendo por princípio e pilar de sustentação a prática do cooperativismo no trabalho. Segundo Shigeo Mizoguchi (1980, p.30):

A cooperação, tida como essência do regime, não deveria ser considerada com o espírito de produção coletiva, mas no sentido de evidenciar as diferenciações que cada educando seria capaz de produzir em benefício da eficiência dos trabalhos. Assim, cada aluno deveria ter uma ficha na qual seria registrado o seu coeficiente de trabalho [...]. A Diretoria da Cooperativa, eleita pelos alunos, composta de um presidente, um secretário e um tesoureiro, deveria incumbir-se da administração geral da Comunidade de Trabalho e, conseqüentemente, da Cooperativa Agrícola. [...] Os lucros resultantes dos trabalhos deveriam ser distribuídos nesta proporção: $70 \%$ aos produtores; $20 \%$ ao patrimônio social; $8 \%$ às despesas gerais da cooperativa e $2 \%$ ao Agente Comercial. Um escritório comercial de escrituração, estatística, correspondência, fichários e um Banco Escolar para estimular e favorecer a economia individual e coletiva; a escola prática de atividades financeiras.

Em 1942, foram criadas dez escolas destinadas ao ensino agrícola, que receberam a 
denominação de Escolas Práticas de Agricultura, nos municípios de: Ribeirão Preto, Rio Preto, Pirassununga, Marília, Itapetininga, Guaratinguetá, Bauru, Araçatuba, Amparo e Presidente Prudente.

As Escolas Práticas de Agricultura subordinadas à Secretaria da Agricultura, Indústria e Comércio, através da Diretoria de Ensino Agrícola e diferenciavam-se das Escolas Profissionais Agrícolas Industriais e Mistas (Pinhal, Jacareí e São Manuel), pois, tinham objetivos essencialmente práticos, destinavam-se a receber alunos semi-alfabetizados ou analfabetos, do sexo masculino.

Entretanto tais escolas também não lograram êxito. Segundo Shizeo Mizoguchi (197?, p.9) "as escolas criadas e instaladas segundo o plano do Dr. Fernando Costa não resistiram, entretanto, ao impacto dos problemas surgidos na difícil empresa de levar avante, ao mesmo, tempo duas organizações de vulto, isto é, uma escola e uma fazenda, entrando em decadência."

A sistematização do ensino agrícola no país, ocorre somente em 1946, mediante a Lei Orgânica do Ensino Agrícola. Relembramos que Ensino Agrícola no Estado de São Paulo situa-se num contexto mais amplo, isto é, subordina-se também à legislação federal de ensino. Neste sentido cabe destacar novamente as disposições contidas na então Lei Orgânica do Ensino Agrícola e suas implicações no embrionário sistema de ensino agrícola paulista. Tal lei era composta por três Decretos-Leis respectivamente:

a) Decreto-Lei $n^{\circ} 9.613$ de 20/8/1946, publicado no DOU em 23/08/96. Seu Artigo $1^{\circ}$ estabelecia "as bases de organização e de regime do ensino agrícola, ramo de ensino até o segundo grau, destinado essencialmente à preparação profissional dos trabalhadores da agricultura" (MIZOCUCHI, 197-?, p. 4);

b) Decreto-Lei no 9.614 de 20/8/1946, publicado no Diário Oficial de 23/8/46, cujo Artigo $1^{\circ}$, determinava que o Ministro da Agricultura deveria fazer a expedição de instruções necessárias à imediata adaptação dos estabelecimentos de ensino agrícola, ora mantidos pelas administrações estaduais e municipais ou pelas instituições particulares, aos preceitos de organização e de regime escolar da Lei Orgânica do Ensino Agrícola, bem ainda estabelecer o processo mediante o qual esses estabelecimentos de ensino poderiam obter a equiparação ou reconhecimento. [...]. O seu parágrafo único também determinava a expedição de instruções a fim de regular o prosseguimento da vida escolar dos alunos matriculados nos estabelecimentos de ensino que, na forma do referido artigo, viessem a obter a equiparação ou o reconhecimento. (MIZOCUCHI, 197-?, p. 4);

c) Decreto no 21.667 de 20/8/1946, publicado no Diário Oficial da União de 24/8/46, 
que determinava o Regulamento dos Currículos de Ensino Agrícola, e que foi posteriormente substituído pelo Decreto nº 38.042 de 10/10/1955.

Para a implantação da Lei Orgânica foi concedido um período de transição. Em 1950 o Ministério da Agricultura publicou a Portaria $n^{\circ} 266$, determinando os critérios para o processo de equiparação e para o reconhecimento das instituições escolares que ofereciam o ensino agrícola no Brasil.

Em 1954, no Estado de São Paulo, as três Escolas Profissionais Agrícolas Industriais e Mistas (Espírito Santo do Pinhal, Jacareí, São Manuel) foram transformadas em Escolas Agrotécnicas objetivando atender as disposições estabelecidas pela Lei Orgânica do Ensino Agrícola.

A Década de cinquienta é um período de reestruturação e reorganização do ensino técnico agrícola no Estado de São Paulo. Foram extintas Escolas Práticas de Agricultura de: Ribeirão Preto, Guaratinguetá, Bauru, Itapetininga, Rio Preto, Pirassununga e a Escola Prática de Horticultura instalada em São Paulo (na Barra Funda, criada em 1947), mantendo-se apenas a de Presidente Prudente.

Em 1951 a Superintendência de Ensino Profissional passou a denominar-se Departamento do Ensino Profissional. O Departamento do Ensino Profissional elaborou um amplo plano para a revitalização da situação deficitária em que se encontrava o ensino agrícola paulista, podendo-se destacar as seguintes ações:

a) criação de novas escolas e adequação do ensino aos princípios, fins e objetivos das mesmas;

b) criação de novos cursos de complementação;

c) recrutamento de profissionais habilitados (médicos veterinários, engenheiros agrônomos etc) para o corpo docente as escolas.

Dentre as ações propostas pelo Departamento de Ensino Profissional, pode-se destacar ainda a:

a) revisão e organização de novos programas de cultura geral e cultura técnica;

b) atualização de recursos didático-pedagógicos e recursos tecnológicos (equipamentos, implementos agrícolas, maquinários etc);

c) adequação das Escolas Profissionais Agrícolas Industriais Mistas de Pinhal, Jacareí e São Manuel às disposições da Lei Orgânica do Ensino Agrícola (Lei Federal no 9.613 de 20 de agosto de 1946). 
Em 1952, tramitava no Departamento do Ensino Profissional a elaboração de planos que visavam a transformação dos Cursos Práticos de Ensino Profissional em Escolas Artesanais e Escolas de Iniciação Agrícola. Os Cursos Práticos que se caracterizavam como pequenas escolas profissionais que funcionavam sobretudo no interior do Estado, obedeciam à legislação estadual e não davam aos seus egressos acesso aos cursos básicos industriais. A transformação destes em Escolas Artesanais ou de Iniciação Agrícola possibilitaria aos seus alunos a continuidade de estudos nos cursos técnicos.

Em 1954, a Lei nº 2.663 determina a transformação dos Cursos Profissionais Práticos em Escolas Artesanais ou Escolas de Iniciação Agrícola. As Escolas de Iniciação Agrícola tinham por objetivo formar o operário agrícola, mantinham cursos com duração de dois anos, permitindo a seus concluintes a possibilidade de ingressarem nos cursos de Mestria Agrícola (das Escolas Profissionais Agrícolas Industriais). Constituiriam assim a infra-estrutura do ensino agrícola no Estado de São Paulo.

Neste ano, as Escolas Profissionais Agrícolas Industriais Mistas foram transformadas pela Lei $\mathrm{n}^{\circ}$ 2.521, de 12 de janeiro, em Escolas Agrotécnicas. Tal transformação permitiu oferecer aos seus egressos o direito de acesso ao ensino de $2^{\circ}$ ciclo. Nessa época ocorre a inclusão da disciplina de Mecânica Agrícola no currículo das Escolas Agrotécnicas.

Em 1956, tem início o segundo ciclo de evolução do Ensino Agrícola com a transferência das Escolas Profissionais Agrícolas Industriais (Agrotécnicas) da Secretaria da Educação para a Secretaria da Agricultura, mais especificamente para a Diretoria do Ensino Agrícola, sendo extintos o Departamento do Ensino Profissional da Secretaria da Educação e o Setor de Cultura Técnica Agrícola.

Todavia as Escolas mantidas em Jacareí e em São Manuel, continuaram subordinadas ao regime estadual,

ministrando um curso médio agrícola em três anos e, outro complementar, de um ano, para a preparação de Auxiliares de Agrônomos, Administradores e Líderes Rurais e passaram a ser consideradas do tipo denominado Escolas de Agricultura, enquanto a de Pinhal, já como Escola Agrotécnica passou a reger-se pelo sistema federal da Lei Orgânica do Ensino Agrícola. (MIZOGHUZI, 197-?, p. 11). 
Esta fase de transição é marcada por entraves e controvérsias, a saber:

a) a Escola Agrotécnica de Espírito Santo do Pinhal passou a funcionar nos termos da Lei Orgânica do Ensino Agrícola, pois na época do decreto de transferência ela já estava em processo de adequação às disposições da Legislação Federal -Lei Orgânica-;

b) as Escolas de Jacareí e São Manuel continuaram por algum tempo subordinadas ao regime estadual, passando a ser denominadas e consideradas Escolas de Agricultura.

Em 1957 foram criadas as Escolas de Iniciação Agrícola, subordinadas à Secretaria da Agricultura, que se constituíam em escolas de nível primário voltadas ensino agrícola que ofereciam cursos de dois anos de duração.

Nesse período o Estado de São Paulo passou a contar com 157 escolas de Iniciação Agrícola, subordinadas à Secretaria da Agricultura, embora nem todas essas unidades escolares tivessem sido plenamente instaladas.

A primeira das Escolas de Iniciação Agrícola a ser fundada foi a de Monte Aprazível em 1957, quando já havia sido extinto o Departamento do Ensino Profissional da Secretaria da Educação e as escolas passaram, então, a subordinar-se à Diretoria do Ensino Agrícola da Secretaria da Agricultura. No mesmo ano, 1957, também foi criada a Escola de Iniciação Agrícola de Rancharia, e em 1960 a Escola de Iniciação Agrícola de Itu. Em 1961 a criação de mais uma escola no município de Jaboticabal e, em 1962, nos municípios de Guapiassu, Bálsamo, General Salgado, Indiaporã, Jales, Macaubal, Neves Paulista e Uchoa. E em 1963 foram criadas dez Escolas de Iniciação Agrícola nos municípios de: Santa Rita do Passa Quatro, São Simão, Franca, Igarapava, Garaimbê, Pederneiras, Vera Cruz, Mirassol, Miguelópolis e Jaú.

Cabe mencionar ainda o Instituto de Zootecnia e Indústrias Pecuárias "Fernando Costa”, em Pirassununga, vinculado à Faculdade de Medicina Veterinária da Universidade de São Paulo que funcionava na antiga Escola Prática de Agricultura de Pirassununga e oferecia dois cursos em nível médio (Laticínios e Zootecnia). Em 1957, esse Instituto foi transferido para a Universidade de São Paulo.

No entanto, já em 1961, a situação da rede de escolas paulistas que ofereciam o ensino agrícola era bastante diversa; compunha-se por apenas nove escolas:

a) cinco escolas de nível primário: Escola Prática de Agricultura de Presidente Prudente; Escola Prática de Horticultura de Jundiaí; Escola de Iniciação Agrícola de Rancharia ; Escola de Iniciação Agrícola de Monte Aprazível ; Escola de Iniciação Agrícola de Itu.

b) quatro Escolas Agrícolas de nível médio: Escola Agrotécnica “Dr. Carolino da 
Motta e Silva", em Pinhal; Escola Agrotécnica "José Bonifácio", de Jaboticabal; Escola de Agricultura "Cônego José Bento", em Jacareí; Escola de Agricultura "Dona Sebastiana de Barros", em São Manuel.

Este contexto histórico revela as dificuldades, impasses e descaminhos do Ensino Técnico Agrícola no Estado de São Paulo. Situação esta paradoxal, considerando-se a iniciativa pioneira deste Estado nas tentativas de organização da educação profissional técnica da área de agropecuária. A evolução do ensino agrícola paulista é marcada, desde sua gênese por descontinuidades, indefinição político-administrativo quanto à competência para sua gestão e oferecimento, representada pelas constantes transferências compulsórias para diferentes órgãos e Secretarias, via ações do poder executivo, por intermédio de decretos estaduais. As palavras de Mizoguchi (197-?, p.13) exprimem com clareza este fato: [...] para apontar as causas que cercearam até há bem pouco tempo a natural expansão iniciada pelo pioneirismo dessa atividade educacional no Estado, seria necessária uma análise crítica apurada das condições e possibilidades administrativas, técnicas, educacionais, econômicas, especificamente socais e políticas [...]. Ainda conforme esclarece o referido pesquisador,

\footnotetext{
Apenas poderíamos mencionar aqui, entre as causas que entravaram a evolução do ensino agrícola no Estado, as de caráter didático-pedagógico, vinculadas à dualidade de direção decorrente do fato de tem sido algumas escolas de ensino da agricultura subordinadas à Secretaria da Educação e outras à Secretaria da Agricultura; tal dualidade de direção, dentre os inevitáveis inconvenientes que acarretou, criou ainda um clima de hesitações e incertezas no setor de ensino médio agrícola estadual, o qual em algum sentido explica a decadência de certas escolas, a ponto de ter sido o ensino de agricultura extinto nelas e suas dependências utilizadas para outras finalidades. (MIZOGHUZI, 197-?, p. 13).
}

A publicação da primeira Lei de Diretrizes e Bases da Educação Nacional no 4.024, de 20 de dezembro de 1961, reconfigura o cenário educacional brasileiro provendo também alterações no ensino técnico agrícola.

Em 1963 o Ensino Técnico Agrícola Paulista retorna à jurisdição da Secretaria da Educação. Neste mesmo ano, o Decreto Estadual n ${ }^{\circ}$ 42, de 5 de julho, transfere as escolas agrícolas e toda a Diretoria do Ensino Agrícola da Secretaria da Agricultura para a Secretaria da Educação. Este é o marco histórico para a consolidação do ensino agrícola no Estado de São Paulo.

Em 1964, são criados quarenta e um ginásios agrícolas estaduais. Neste mesmo ano as Escolas de Iniciação Agrícola e as Escolas Agrícolas são transformandas em Ginásios Agrícolas, e as Escolas Agrotécnicas transformam-se em Colégios Agrícolas.

Até então, o ensino agrícola contava com 16 escolas de iniciação agrícola, 5 ginásios 
e 3 colégios e segundo o parecer do governador Roberto C. de Abreu Sodré constituía “ uma grave lacuna do sistema educacional de São Paulo, com reflexos altamente negativos nos esforços para o desenvolvimento da agricultura paulista e mesmo nacional, que de forma crescente e inadiável estavam a exigir pessoal qualificado em vários níveis, para a difusão e a implantação de novas técnicas.” (MIZOGHUZI, 197-?, p. 9).

Os Colégios Técnicos Agrícolas, de grau médio, foram criados em 1968, pelo Decreto 51.094, de 16/12, em dezoito municípios paulistas: Santa Rita do Passa Quatro, São Simão, Cabrália Paulista, Cândido Mota, Cerqueira César, Franca, Graça, Igarapava, Itu, Itapetininga, Jundiaí, Miguelópolis, Mirassol, Monte Aprazível, Paranapanema, Quatá, Rancharia e Vera Cruz.

A autorização de instalação do $2^{\circ}$ Ciclo é feita pelo Secretário da Educação, através do ATO n 45, de 28/02/69, nos municípios de Santa Rita do Passa Quatro, Monte Aprazível, Franca, Igarapava, Vera Cruz, Rancharia e Jundiaí, Presidente Prudente e "Cônego José Bento", em Jacareí.

A década de setenta marca a expansão e a reestruturação do Ensino Técnico Agrícola no Estado de São Paulo, caracterizado por um novo sistema de ensino denominado EscolaFazenda, criado pelo Prof ${ }^{\mathrm{e}}$ E Engenheiro Agrônomo Sigheo Mizoguchi.

O Sistema Escola-Fazenda é basicamente, um processo educativo que se propõe desenvolver organismos escolares de ensino agrícola economicamente autosuficientes e que proporcionem condições de trabalho e da aprendizagem em situações de vida prática. [...] A filosofia do Sistema Escola-Fazenda tem como princípio o desenvolvimento das habilidades, destrezas, e experiências indispensáveis à fixação dos conhecimentos adquiridos nas aulas teóricas. Assim, a Escola-fazenda vem a ser uma escola dinâmica que educa integralmente, porque familiariza o educando com atividades semelhantes às que terá de enfrentar na vida real, em sua convivência com os problemas da agropecuária, conscientizando-o, ainda, de suas responsabilidades e possibilidades. Em síntese é o "aprender a fazer" e "fazer para aprender. (MIZOGUCHI, 1980, p 7).

Cada Escola-Fazenda, tinha por objetivo principal formar o Agricultor Polivalente Independente, e era concebida enquanto um organismo educacional, composto por quatro áreas distintas e fundamentais : a) a Área de Cultura Geral e Tecnológica, onde se desenvolviam as atividades destinadas à aprendizagen teórico-prática em sala de aula; b) Área de atividades em Laboratórios de Prática e Produção ( LPP), “destinada a demonstração práticas pelos professores e experimentação pelos alunos" (MIZOGUCHI, 1980, p. 29); c) Área de Atividades em Programa Agrícola (PAO) caracterizada por um conjunto de projetos agropecuários, cuja principal finalidade era "desenvolver habilidades e destrezas, até um nível último de eficiência, auto-iniciativa, capacidade administrativa e cooperação entre os alunos" 
(MIZOGUCHI, 1980, p 30). Cabe destacar que os projetos eram de responsabilidade dos alunos que recebiam orientação e supervisão dos professores das disciplinas às quais se referiam; d) Área da Cooperativa-Escola (Coop), que segundo Mizoguchi (1980, p. 30) "é o componente chave da Escola-Fazenda, que irá permitir o pleno funcionamento dos sistema, em direção a seus objetivos"

O Sistema Escola-Fazenda alcança êxito imediato e reconhecimento das autoridades competentes e acaba por se tornar o modelo padrão do ensino agrícola no Estado de São Paulo.

Os anos setenta, constituem por assim dizer, a época áurea, do ensino agrícola no Estado de São Paulo. Ocorre significativa expansão, contando com 35 instituições escolares. Os cursos eram estruturados em dois níveis: $1^{\circ}$ ciclo que correspondia ao ginasial, e $2^{\circ}$ ciclo para a formação do Técnico Agrícola, com duração de três anos.

Ressalta-se que, em meados da década de setenta a Habilitação Profissional oferecida preponderantemente nos Colégios Técnicos Agrícolas, era a de Técnico em Agropecuária. Em 1976, o Decreto Estadual $n^{\circ} 7510$ reorganiza a Secretaria da Educação e extingue a Coordenadoria do Ensino Técnico, que comportava a Diretoria do Ensino Agrícola, subordinando as escolas agrícolas à Coordenadoria de Ensino do Interior.

A Resolução SE de 27/05/1977 dispôs sobre a regularização das Habilitações de Técnico Agrícola e de Técnico em Agropecuária.

O Curso de Técnico em Agricultura passa se denominar Técnico Agrícola, e era oferecido em 13 escolas, conforme dispunha a supracitada Resolução:

Fica autorizado o funcionamento da habilitação de Técnico Agrícola, a partir de 1968 ou 1969, nos 13 estabelecimentos adiante mencionados, que a ministraram até 1972 ou 73: EESG Prof Luiz Pires Barbosa de Cândido Mota, EESG Carmelito Correa Júnior de Franca, EESG de Igarapava, EESG José Bonifácio de Jaboticabal, EESG Benedito Storano de Jundiái, EESG de Monte Aprazível, EESG Carolino da Mota e silva de Pinhal, EESG de Presidente Prudente, EESG de Rancharia, EESG "Manoel dos Reis Araújo" de Santa Rita do Passa Quatro, EESG de D. Sebastiana de Barros de São Manoel e EESG Paulo Guerreiro Franco de Vera Cruz. (SÂO PAULO. 1977).

A Habilitação Profissional Plena de Técnico em Agropecuária foi igualmente autorizada, para funcionamento em 28 unidades, sendo esta a Habilitação predominantemente, nas escolas, a saber:

Fica igualmente autorizada a Habilitação de Técnico em Agropecuária, nos 28 estabelecimentos adiante mencionados e que a iniciaram em 1973 ou 1974: EESG Agrícola de Adamantina "Engenheiro Herval Bullusci", EESG Agrícola de 
Cafelândia, EESG Agrícola de Dracena, EESG Agrícola de Franca "Prof. Carmleino Correa Júniro", EESG Agrícola de Graça "Dep. Paulo Ornelas C. Barros”, EESG Agrícola de Igarapava, EESG agrícola de Iguape, EESG Agrícola de Itapeva "Dário Pacheco Pedrosos, EESG de Itu, "Martinho Di Ciero", EESG Agrícola de Jacareí “Cônego José Bento", EESG Agrícola de Jáu, "prof. Urias Fereira, EESG Agrícola de Jundiaí "Benedito Storano", EESG Agrícola "Laurindo Alves de Queiroz", EESG Agrícola de Mirassol, EESG Agrícola de Monte Aprazível, EESG Agrícola de Paraguaçu Paulista "Augusto Tortorelo de Araújo", EESG Agrícola de Penápolis “João Jorge Geraissate", EESG Agrícola de Pinhal "Carolina Mota e Silva”, EESG Agrícola de Presidente Prudente, EESG Agrícola de Quatá, EESG Agrícola de Rancharia, EESG Agrícola de Rio das Pedras "Dr. José Coury”, EESG Agrícola de Santa Cruz do Rio Pardo, EESG Agrícola de Santa Rita do Passa Quatro "Manoel dos Reis Araújo", EESG Agrícola de São Manoel "Dra Sebastiana de Barros", EESG Agrícola de Vera Cruz "Paulo Guerreiro Franco", EESG Agrícola de Votuporanga. (SÂO PAULO. 1977).

Nesta década de setenta, "a partir da caracterização do comportamento econômico do setor primário e da definição das prioridades educativas nesse setor, frente aos objetivos da integração nacional, foi possível identificar o profissional adequado ao desenvolvimento, das zonas rurais no país.” (MIZOGUCHI,1980, p. 39)

O técnico agrícola foi concebido como agricultor independente polivalente, ou agente de produção, sendo que seus conhecimentos e habilidades deveriam permitir também que ele atuasse como agente de serviços. Assim, a Habilitação Profissional de Técnico em Agropecuária visava principalmente a formação do agricultor independente polivalente, e adquire significativa relevância. As demais habilitações profissionais do setor primário eram determinadas a partir da Habilitação de Agropecuária. No então parecer de Mizoguchi (1980, p. 55) a Habilitação de Técnico em Agropecuária - “ de acordo com a análise das condições para o desenvolvimento da economia primária constituía-se a prioridade máxima para a educação na conjuntura atual do país, sendo a única que englobava, com a mesma intensidade, todas as disciplinas decorrentes do currículo básico para a formação do Agricultor Independente Polivalente."

Nesse sentido podem ser consideradas como ocupações básicas do técnico agrícola o planejar, o organizar, enfim administrar/gerenciar a pequena e média propriedade, de maneira autônoma ou em sistema cooperativista, tendo produtividade e equilíbrio econômico. No entanto, conforme argumenta Mizoguchi (1980, p. 43) o agricultor polivalente independente,

considerado isoladamente não está completo para o desempenho de sua missão[...] É, pois, a família,e não o indivíduo, o agente de desenvolvimento sócio-econômico [...] Sendo assim, compete ao ensino agrícola habilitar a jovem do meio rural que como esposa ou como profissional participará, ao lado do agricultor independente polivalente, da função de agente de desenvolvimento social e econômico do meio rural.

Neste contexto, tem-se a Habilitação de Técnico em Economia Doméstica, como 
uma Habilitação destinada às jovens do meio rural. A economista doméstica atuaria como agente de integração familiar e social, desempenhando as funções de planejamento, administração e execução das atividades domésticas do meio rural.

Havia ainda, o sub setor da área de agropecuária, composta por outras habilitações propostas pelo Conselho Federal de Educação (CFE), sendo consideradas habilitações afins: o Técnico em Agricultura e Técnico em Pecuária.

A Reforma Administrativa da Secretaria da Educação, objetivando adequá-la às disposições da Lei Federal no 5692/71, constitui-se noutro aspecto importante para a evolução do Ensino Agrícola no Estado de São Paulo.

Já no início da década de oitenta, na gestão de Franco Montoro e Paulo Tarso dos Santos (na Secretaria da Educação) foi constituído um importante canal de participação: O Fórum de Educação do Estado de São Paulo, tendo sido o Ensino Técnico em São Paulo o tema específico da II Sessão Pública, em novembro de 1983. Segundo a Prof ${ }^{a}$ Lourdes Marcelino Machado:

O documento base da Associação dos Professores do Ensino Oficial do Estado de São Paulo - APEOESP- apontava para o Histórico do Movimento dos Professores das Escolas Técnicas. Documento: denúncia a transferência de seis escolas técnicas para o Centro Paula Souza, da UNESP, no apagar das luzes da gestão Ferreira Martins, e a seguir as propostas aprovadas em dois Encontros de Escolas Técnicas da rede pública do Estado de São Paulo.Em relação à administração das escolas, a reivindicação era a de criação de uma Coordenadoria do Ensino Profissionalizante. (MACHADO, 1992a, p. 81)

Em resposta às discussões, debates e reivindicações do Fórum foi criado posteriormente, em 1984, o Grupo Executivo de Trabalho do Ensino Agrícola (GEAGRI).

Em 1985 criou-se a Divisão de Supervisão e Apoio às Escolas Técnicas Estaduais (DISAETE). A esta coube a responsabilidade de administrar as escolas técnicas industriais e agrícolas, e o fez até 1991.

Em 1991, tem início o quarto ciclo de evolução histórica do Ensino Técnico Agrícola, ou seja, constata-se sua quarta transferência compulsória, mediante Decreto, para uma nova Secretaria Estadual.

O Decreto Estadual $n^{\circ} 34.032 / 91$, de 22 de outubro, determinou a transferência da Divisão de Supervisão e Apoio às Escolas Técnicas Estaduais (DISAETE), com as suas escolas, da Secretaria da Educação para a Secretaria de Ciência, Tecnologia e Desenvolvimento Econômico. Seu Artigo $1^{\circ}$ estabeleceu a transferência, a partir de $1^{\circ}$ de janeiro de 1992, com seus bens móveis, semoventes, máquinas, equipamentos e implementos agrícolas, direitos e obrigações, cargos e funções-atividades, da Secretaria da Educação para a 
Secretaria da Ciência e Tecnologia e Desenvolvimento Econômico, a Divisão de Supervisão e Apoio às Escolas Técnicas Estaduais com suas escolas, constante do Anexo integrante do referido decreto. (SÃO PAULO, 1991).

Nos termos do seu Artigo $2^{\circ}$ a Divisão de Supervisão e Apoio às Escolas Técnicas Estaduais (DISAETE) passou a denominar-se Divisão Estadual de Ensino Tecnológico (DEETE). Enquanto seu Artigo $3^{\circ}$ determinava que a administração de bens imóveis utilizados pelas Escolas Técnicas Estaduais constante do Anexo que integrava este decreto, ficava transferida, a partir de $1^{\circ}$ de janeiro de 1992, à Secretaria da Ciência, Tecnologia e Desenvolvimento Econômico. (SÃO PAULO, 1991).

O Artigo $7^{\circ}$ do Decreto Estadual em questão, dispôs sobre o afastamento dos integrantes do quadro do magistério da Secretaria da Educação junto à Secretaria da Ciência, Tecnologia e Desenvolvimento Econômico, a saber:

\footnotetext{
Exclui-se do disposto neste decreto os integrantes do Quadro do Magistério da Secretaria da Educação, classificados nas Escolas Técnicas Estaduais abrangidas por este decreto que, por meio de ato do Titular da Pasta, serão classificados em outras unidades escolares da Secretaria da Educação.

Parágrafo Único- Os abrangidos pelo “caput”poderão, mediante opção, ser afastados junto à Secretaria da Ciência, Tecnologia e Desenvolvimento Econômico, sem prejuízo dos vencimentos ou salários e das demais vantagens dos cargos ou das funções -atividades.Total de 35 escolas. (SÃO PAULO, 1991).
}

Em 1993 as Escolas Técnicas Estaduais foram novamente transferidas, por meio do Decreto $n^{\circ} 37.735 / 93$, para o Centro Estadual de Educação Tecnológica "Paula Souza" (CEETEPS ou CPS), autarquia estadual, de regime especial, na época vinculada e associada à Universidade Estadual Paulista "Júlio de Mesquita Filho" (UNESP) e subordinada à Secretaria de Secretaria da Ciência e Tecnologia e Desenvolvimento Econômico. Vale lembrar que o CPS foi criado na vigência do regime militar, diante das novas demandas do setor econômico-produtivo e da expansão industrial paulista que demandavam formação profissional, mediante Decreto-Lei s/n de 6 de outubro de 1969, pelo Governador Roberto Costa de Abreu Sodré. Assim, então constituído na condição de entidade autárquica, com personalidade jurídica e patrimônio próprio, com sede e foro na cidade de São Paulo vinculado administrativamente naquele momento à Secretaria de Estado dos Negócios da Educação, e financeiramente à Secretaria da Fazenda. Cuja criação visava à articulação, a realização e o desenvolvimento da educação tecnológica, nos graus de ensino médio e superior pública no Estado de São Paulo.Vale destacar que o Centro Paula Souza desempenha desde sua criação um importante papel no desenvolvimento da educação profissional e tecnológica pública no contexto brasileiro. 
O Decreto Estadual $n^{\circ} 37.735$, de 27/10/93, que instituiu esta transferência apresentava a seguinte argumentação:

\begin{abstract}
Considerando a emergência de novas categorias profissionais, em virtude de uma crescente sofisticação tecnológica, impõe-se a necessidade de formação de mão-deobra capaz não simplesmente de aplicar, mas sobretudo de compreender, questionar e decidir sobre a realidade tecnológica nacional;

Considerando a importância do Ensino Técnico, enquanto nível de ensino cujo papel preponderante deve ser a transmissão de meios para atuar num segmento vital para autonomia nacional, como é o caso da tecnologia, não devendo se restringir a mero reprodutor de um saber destinado apenas a administrar pacotes tecnológicos;

Considerando a necessidade de articulação do ensino médio com o superior, visto que a este cabe a tarefa de habilitar para a proficiência técnica nos diversos campos de especialização, de forma a acompanhar a demanda de uma sociedade, onde se observam contínuas evoluções tecnológicas;

Considerando a importância de reunir em rede única as Escolas Técnicas Estaduais para fins de fixação de uma política de atuação com relação a esse ensino, conforme preceito constitucional;

Considerando que o Centro Estadual de Educação Tecnológica "Paula Souza"CEETEPS, autarquia de regime especial, vinculada e associada à Universidade Estadual Paulista "Júlio Mesquita Filho "- UNESP, foi criado pelo Decreto- lei de 6 de outubro de 1969, justamente com a finalidade de manter o ensino técnico e tecnológico." (São Paulo. 1993)
\end{abstract}

$\mathrm{O}$ artigo $1^{\circ}$ do Decreto dispôs sobre a transferência das Escolas Técnicas Estaduais relacionadas nos Anexos I e II deste decreto, a partir de $1^{\circ}$ de janeiro de 1.994, respectivamente, da Secretaria da Ciência, Tecnologia e Desenvolvimento Econômico e da Secretaria da Educação para o Centro Estadual de Educação Tecnológica 'Paula Souza'CEETEPS. (São Paulo. 1993).

Dessa forma, o CPS criado em 1969 responde pelo oferecimento da educação profissional e tecnológica pública, nos níveis básico, técnico, tecnológico e de pós-graduação no Estado de São Paulo. Em 2001, data deste estudo, o Centro Paula Souza (CPS) compreendia: a) 64 Escolas Técnicas Estaduais - ETEs (cursos técnicos na áreas industrial e de serviços); b) 35 Escolas Técnicas Agrícolas Estaduais- ETAEs (cursos técnicos na área agrícola), cuja denominação foi alterada também para ETE ( Escola Técnica Estadual), conforme Decreto Estadual n ${ }^{\circ} 44.500 / 99$; c) 09 Faculdades de Tecnologia - FATEC's (cursos superiores de tecnologia); d) 12 Classes descentralizadas em convênio com prefeituras municipais (cursos médio e técnicos dos diversos setores produtivos). No total, as 108 (cento e oito) Unidades de Ensino e as 12 (doze) Classes Descentralizadas distribuídas em 94 municípios paulistas. Já em janeiro de 2008, o Centro Paula Souza administrava 171 Unidades de Ensino, sendo (138) Escolas Técnicas Estaduais (ETEs) e (33) Faculdades de Tecnologia (Fatecs) localizadas em cento e dezesseis (116) cidades paulistas que atendem a mais de cento e vinte mil alunos. Ocorre durante os anos de 2001 a 2008 um processo de 
expansão do CPS com crescimento do número de Escolas Técnicas Estaduais e das Faculdades de Tecnologia. As agora denominadas Escolas Técnicas (ETECs) contavam no referido ano com mais de 100 mil estudantes nos níveis de ensino Médio e Técnico, para os setores Industrial, Agropecuário e de Serviços, distribuídos em mais de 78 habilitações. As FATECS (em janeiro de 2008) contavam com 20 mil alunos então distribuídos em 31 cursos Superiores de Graduação. Totalizando, na referida data (33) Faculdades de Tecnologia. Nos dias atuais estão bem diferenciados pois é ocorre de fato uma grande ampliação de ETECs e FATECs.

Entretanto, apesar do pioneirismo do Estado de São Paulo e da exitosa iniciativa de organização de uma importante rede pública de educação profissional e tecnológica, observase que a trajetória do ensino técnico agrícola é marcada pela transição, ruptura e descontinuidade nas políticas governamentais direcionadas à gestão deste ensino. Fato este que afetou diretamente a elaboração e implementação de projetos político-pedagógicos concernentes à área agrícola e a gestão das suas instituições escolares. Isto pois,

\footnotetext{
"um governo não é inteiramente demiurgo do seu projeto público. A implementação de sua proposta é dependente da capacidade que demonstre de agregar atores sociais a ela; ao adquirir corpo, o projeto público já não se rege nos termos estritos de sua formulação original, pois redimensiona-se incorporando significações políticas dos atores que agrega. [...] a possibilidade de implementação de uma política decorre de sua capacidade de agregar os sujeitos civis previamente existentes, tornando-os atores políticos; ou mesmo de gestá-los, por um processo político que resulta em complexificação de interesses no seio da sociedade civil." (ROCHA, 1991: 2-4).
}

Fato este que nos remete a reflexão quanto às formas de elaboração e implementação das políticas educacionais e de seus impactos no interior da escola. Vale ressaltar que o período de 2000 a 2014 demanda a realização de novas pesquisas de campo constituindo-se em rica trajetória político-normativa. Por sua vez, a trajetória histórico-organizacional das denominadas Escolas Técnicas Agrícolas Estaduais (atualmente denominadas Escolas Técnicas Estaduais) configurou-se também em temática correlata e abordada em pesquisa financiada pela Fapesp. (2011-2013) ora implementada pela presente pesquisadora.

\section{CONSIDERAÇÕES FINAIS}

A investigação e ou estudo das atuais políticas públicas educacionais, em especial, da educação profissional e tecnológica, requer a análise da trajetória histórica-normativa, bem como identificar a sua gênese. É preciso identificar as múltiplas determinações históricas que 
delinearam e conduziram a evolução da educação profissional de nível técnico da área agropecuária (primária) na sociedade brasileira, com o intuito de oferecer maiores subsídios teóricos que possam contribuir para o atual debate sobre esta temática. O ensino agrícola desenvolveu-se à luz de estereótipos e no isolamento de escassas análises e críticas científicas, enquanto raro objeto de pesquisa.

Seguindo a trilha da história, chegamos à contemporaneidade. Podemos dizer que a trajetória do ensino técnico agrícola paulista é marcada pela transição via decretos, ruptura e descontinuidade nas políticas educacionais interferindo diretamente na construção de seu projeto pedagógico. O ensino técnico agrícola no Estado de São Paulo foi submetido a constantes indefinições políticas quanto aos seus princípios e fins. As suas várias transferências e realocações passando por diferentes Secretarias Estaduais revelam os entraves políticos quanto à sua gestão e a dificuldade de situá-lo em um locus apropriado e condizente aos seus fins.

A trajetória das Escolas Agrícolas e do Ensino Técnico Agrícola Paulista é contada por decretos, ou seja, é a história dos Decretos e da ação do poder executivo sobre uma temática tão relevante no campo pedagógico-social. As transferências compulsórias, via Decretos Estaduais, revelam ainda a exclusão e o cerceamento das vias de participação dos sujeitos sociais nos destinos desta área do ensino técnico. As motivações de tais realocações apontam para questões de ordem político-econômicas e administrativas, enquanto que a dimensão pedagógica foi pouco valorizada, visto que a definição das diferentes políticas educacionais destinadas ao ensino técnico agrícola, ao longo da sua evolução, ocorre de forma impositiva, não havendo a efetiva participação dos sujeitos escolares.

Verifica-se que a transição em órgãos gestores e a ruptura na consolidação de um projeto pedagógico-curricular e na sistemática de organização institucional das escolas técnicas agrícolas são os fatores caracterizadores do oferecimento do ensino técnico agrícola paulista. É válido afirmar que essas mudanças afetaram a construção de sua identidade, pois se indagava a cargo de qual Secretaria Estadual o ensino técnico agrícola, efetivamente, deveria estar vinculado. As transições revelam a descontinuidade na política de formação profissional e a dificuldade para a constituição de um projeto político-pedagógico para essa área profissional. Isso constitui um dos componentes que fragilizaram o ensino técnico Agropecuário no Estado de São Paulo, contribuindo para desencadear um processo de descaracterização. Essas questões foram constatadas em pesquisa de mestrado (2002), que abordou a reforma da legislação federal e da política da educação profissional de nível técnico e seus impactos para a gestão das Escolas Técnicas Agrícolas e na sistemática de 
oferecimento do ensino técnico da área agropecuária no Estado de São Paulo.

O grande desafio da pesquisa referiu-se à abordagem metodológica de nosso objeto de estudo e ao trabalho de garimpagem de informação/dados. Sem a pretensão de apresentarmos pareceres definitivos encontramos, nesta caminhada, incertezas e indagações de diversas ordens. Em visão macro buscamos identificar, primeiramente, a trajetória do Ensino Técnico Agrícola no Brasil, do período colonial ao século XXI (2001) a fim de ressaltar os aspectos relevantes da sua especificidade. Em segunda instância, buscamos contextualizar a trajetória do Ensino Técnico Agrícola no Estado de São Paulo (1882 a 2001). Situação paradoxal foi identificada em relação a esse Estado destacado pela ação de vanguarda na criação, manutenção e fomento da importante rede de educação profissional e tecnológica pública, em especial, pelo oferecimento do próprio ensino técnico agrícola público. No entanto, a gestão deste ensino é também marcada pelos traços de indefinição e contradições das políticas quanto à efetiva valorização do seu papel social. Isto pois, procuramos subsídios que pudessem auxiliar a análise interpretativa da sua configuração atual. Por fim, vale reconhecer que no estudo da trajetória do ensino técnico agrícola nos sistemas de ensino (federal e estadual paulista) defrontamo-nos, em ambos os casos, com a complexidade de acesso direto às fontes, de preservação de documentos, e de análise dos dados históricos. Nesse sentido, a legislação de ensino constitui a principal fonte de dados para identificar sua trajetória histórica e político-social, em especial, configurando-se o ensino técnico agrícola paulista em raro objeto de pesquisa no âmbito da historia da educação. $\mathrm{O}$ estudo das implicações da reforma da legislação federal de ensino e das políticas curriculares adotadas no âmbito do CPS, a partir da nova LDB 9394/96, foi também objeto de nossa pesquisa a demandar também a análise de sua trajetória. No entanto, no breve espaço deste artigo focalizamos a questão das realocações das unidades escolares e do ensino técnico agrícola nas diversas secretarias estaduais (da sua gênese 1882 a 2001). Assim, em nosso caminho encontramos outras tantas indagações. Fato este que muito nos instiga a dar continuidade a pesquisa na busca de novos referenciais e a fim de abrir espaços para diálogos e reflexões em torno desta temática.

\section{REFERÊNCIAS BIBLIOGRAFICAS}

AZEVEDO, F. A cultura brasileira. São Paulo: EDUSP; Melhoramentos, 1971.

BRASIL. Conselho Federal de Educação. Parecer n 45/72, de 12 de janeiro de 1972. Fixa os mínimos a serem exigidos em cada habilitação profissional ou conjunto de habilitações afins no ensino do $2^{\circ}$ grau. In: BRASIL. Habilitações profissionais no ensino do $2^{\mathbf{o}}$ grau.

Brasília: Expressão e Cultura, 1972. p. 75-133. 
BRASIL. Conselho Federal de Educação. Parecer 108/83, de 11 de março de 1983. Dispõe sobre a Lei n $^{\circ} 7.044 / 81$ e as Habilitações Profissionais. In: Legislação I: apostila completa. São Paulo: Centro Integrado de Ensino, 1988. p. 163-170.

BRASIL. Decreto $n^{\circ} 72.434$, de 9 de julho de 1973. Cria a Coordenação do Ensino Agrícola COAGRI - no Ministério da Educação e Cultura, atribuindo-lhe autonomia administrativa e financeira e dá outras providências. Diário Oficial [da República Federativa do Brasil], Brasília, DF, 10 jul. 1973. In: BRASIL. Ministério da Educação e Cultura. Secretaria de Ensino de $1^{\circ}$ e $2^{\circ}$ graus. Legislação brasileira do ensino de $2^{\circ}$ grau: coletânea dos atos federais. 2. ed. Brasília, DF, 1979. p. 193-194.

BRASIL. Decreto n ${ }^{\circ} 76.436$, de 14 de outubro de 1975. Altera o Decreto $n^{\circ} 72.434$, de 9 de julho de 1973, que criou a Coordenação Nacional do Ensino Agrícola do Ministério da Educação e Cultura. Diário Oficial [da República Federativa do Brasil], Brasília, DF, 15 out. 1975.In: BRASIL. Ministério da Educação e Cultura. Secretaria de Ensino de $1^{\circ}$ e $2^{\circ}$ graus. Legislação brasileira do ensino de $\mathbf{2}^{\mathbf{0}}$ grau: coletânea dos atos federais. 2. ed. Brasília, DF, 1979. p. 195.

BRASIL. Lei Federal no 4.024, de 20 de dezembro de 1961. Fixa as Diretrizes e Bases da Educação Nacional. Diário Oficial [da República Federativa do Brasil], Brasília, DF, 28 dez. 1961. In: BRASIL. Ministério da Educação e Cultura. Secretaria de Ensino de $1^{\circ}$ e $2^{\circ}$ graus. Legislação brasileira do ensino de $2^{\circ}$ grau: coletânea dos atos federais. 2. ed. Brasília, DF, 1979. p. 31-35.

BRASIL. Lei de Diretrizes e Bases da Educação Nacional. Lei n ${ }^{\circ}$ 9.394, de 20 de dezembro de 1996. Estabelece as diretrizes e bases da educação nacional. Diário Oficial [da República Federativa do Brasil], Brasília, DF, 23 dez. 1996. Disponível em:

http://www.mec.gov.br/semtec/educprof/Legislacomum.shtm. Acesso em: 05/06/01.

FERREIRA JUNIOR, A.; BITTAR, M. Educação capitalismo periférico globalizado. Ser social, Brasília, n. 4, p. 153-194, jan./jun. 1999.

MACHADO, L. M. Ensino Agrícola no Estado de São Paulo: introdução ao estudo relação trabalho-educação. 1992. Dissertação (Mestrado em Educação) - Faculdade de Filosofia e Ciências, Universidade Estadual Paulista, Marília, 1992.

MIZOGUCHI, S. Controle de gerência da produção dos centros agrícolas, dentro do Sistema Escola-Fazenda. São Paulo: CENAFOR, 1976.

MIZOGUCHI, S. O Ensino Agrícola no Estado de São Paulo. [197-?]. Não publicado.

MIZOGUCHI, S. Escola-Fazenda: um sistema brasileiro onde o jovem aprende, trabalha e ganha. São Paulo: CENAFOR, 1980. Trabalho apresentado no Seminário Internacional de Educação, Formação Profissional e Emprego nas periferias urbanas, Salvador, 1980.

NAGLE, J. Educação na Primeira República. In: PINHEIRO, P. S. et al. O Brasil

Republicano: Sociedade e instituições (1889-1930). 3. ed. São Paulo: Difel, 1985. v. 2, livro terceiro, cap. 7, p. 259-291. (História Geral da Civilização Brasileira; t. III).

ROMANELLI, O. História da educação no Brasil. Petrópolis: Vozes, 1980.

SÃO PAULO (Estado). Decreto n ${ }^{\circ} 34.032$, de 22 de outubro de 1991. Dispõe sobre a transferência da Divisão de Supervisão e Apoio às Escolas Técnicas Estaduais da Secretaria da Educação para a Secretaria de Ciência, Tecnologia e Desenvolvimento Econômico e dá 
providências correlatas. Diário Oficial [do] Estado de São Paulo, São Paulo, v. 101, n. 201, p. 1, 23 out. 1991. Poder Executivo, Seção 1.

SÃO PAULO (Estado). Decreto no 17.027, de 19 de maio de 1981. Aprova o Regimento do Centro Estadual de Educação Tecnológica "Paula Souza". In: SÃO PAULO (Estado). CEETEPS. Grupo de Informações Documentárias. Regimento do CEETEPS. São Paulo, 1996. p. 1.

SÃO PAULO (Estado). CEETEPS. Grupo de Informações Documentárias. Regimento do CEETEPS. São Paulo, 1996.

SÃO PAULO (Estado). Decreto no 37.735, de 27 de outubro de 1993. Autoriza a transferência das escolas Técnicas Estaduais para o Centro Estadual de Educação Tecnológica "Paula Souza" - CEETEPS e dá providências correlatas. Diário Oficial [do] Estado de São Paulo, São Paulo, p. 7, 28 out. 1993. Poder Executivo, Seção 1.

SÃO PAULO (Estado).Decreto no 42.151, de 5 de julho de 1963. Transfere a administração da Diretoria do Ensino Agrícola da Secretaria da Agricultura para a Secretaria da Educação. Diário Oficial [do] Estado de São Paulo, São Paulo, 06 jul. 1963. Poder Executivo, Seção 1.

SÃO PAULO (Estado). Deliberação CEE 14/97. Fixa diretrizes para a educação profissional no Sistema de Ensino do Estado de São Paulo. Diário Oficial [do] Estado de São Paulo, São Paulo, v. 107, n. 207, p. 6, 28 out. 1997. Poder Executivo, Seção 1.

SÃO PAULO (Estado). Secretaria da Agricultura, Indústria e Comércio. Rasgando Horizontes: a Secretaria da Agricultura no seu cinqüentenário. São Paulo, 1942.

SÃO PAULO (Estado).Resolução SE,de 27 maio de 1977.Dispõe sobre a regularização das Habilitações de Técnico Agrícola e Técnico em Agropecuária.Diário Oficial [do]Estado de São Paulo., p21, 28 de maio de1977.Poder Executivo, Seção I.

SAVIANI, D. Política e educação no Brasil: o papel do Congresso Nacional na legislação de ensino. 4. ed. rev. Campinas: Autores Associados, 1999a. (Coleção Educação Contemporânea).

SÁNCHEZ VÁSQUEZ, A. Filosofia da práxis. 2. ed. Rio de Janeiro: Paz e Terra, 1977.

SILVA, M.L. A Reforma da Educação Profissional de Nível Técnico: impactos e impasses da sobre o Ensino Técnico Agrícola no Estado de São Paulo. 2002. Dissertação (Mestrado em Educação- Área Fundamentos). Programa de Pós-Graduação em Educação, Universidade Federal de São Carlos, São Carlos, 2002.

VELEDA, L. N. Problemas atuais do ensino agrícola no Brasil. 1970. Dissertação

(Mestrado) - Programa de Pós-Graduação em Teoria e Prática de Currículo para Nível Médio, Universidade Federal de Santa Maria, Santa Maria, 1970. 